\title{
SORTE, VirTUde, E ANUlabilidAde EpistÊMicA
}

\author{
JoÃo RizZio VicEnTE FETT
}

\begin{abstract}
Duncan Pritchard has suggested that anti-luck epistemology and virtue epistemology are the best options to solve the Gettier problem. Nonetheless, there are challenging problems for both of them in the literature. Pritchard holds that his anti-luck virtue epistemology puts together the correct intuitions from both anti-luck epistemology and virtue epistemology and avoids their problems. Contra Pritchard, we believe that there is already a satisfactory theory on offer, namely, the defeasibility theory of knowledge. In this essay we intend (i) to examine Pritchard's anti-luck virtue epistemology, and (ii) to defend the defeasibility theory of knowledge as an alternative to Pritchard's theory. We will provide the reader with reasons for believing that the defeasibility theory is better than Pritchard's theory because the former is more economic and more ecumenical than the latter, since it goes without non-epistemic notions and remains neutral as for the internalism vs. externalism debate.
\end{abstract}

Keywords: The Gettier problem; anti-luck epistemology; virtue epistemology; defeasibility theory; Duncan Pritchard.

\section{Introdução}

Imagine um sujeito, $S$, que consulta o seu relógio de parede (analógico) para checar as horas. Por meio da sua percepção, ele passa a crer que são cinco horas, e ele crê verazmente - são, de fato, cinco horas. Até aqui, é plausível supor que a maioria de nós diria que $S$ sabe que são cinco horas. Mas suponha que o seguinte também é verdadeiro neste caso: o relógio de $S$ está parado, e por mera coincidência ele parou há exatamente 12 (ou 24) horas. Aqui, por sua vez, é plausível supor que nenhum de nós diria que $\mathrm{S}$ sabe que são cinco horas, embora isto seja verdadeiro e $S$ creia nisso por meio da sua percepção confiável.

Por que somos levados a pensar que $S$ não tem conhecimento no cenário exposto acima? Trata-se do famoso caso Stopped Clock, de Bertrand Russell (1948, p.154). Qual é o problema? Muitos epistemólogos prontamente responderiam o seguinte: $\mathrm{O}$ problema é a sorte envolvida no alcance da verdade. É por pura sorte que $S$ acaba com uma crença verdadeira sobre o horário, pois é pura sorte que, no momento em que $S$ olhou para o relógio, ele estava parado há exatamente 12 ou 24 horas. Parece a muitos de nós que o conhecimento não pode ser algo tão frágil como é o alcance sortudo da verdade de uma crença. Peter Unger (1968, p.158) sugeriu que esta ideia faz parte da própria explicação do conhecimento. Ele sugeriu que um sujeito, $S$, sabe que $P$ somente se não é um acidente que $S$ está certo quanto ao que ele crê.

Principia 20(2): 179-200 (2016).

Published by NEL — Epistemology and Logic Research Group, Federal University of Santa Catarina (UFSC), Brazil. 
Duncan Pritchard é o responsável por ressuscitar esse modo de falar sobre o conhecimento. Pritchard torna esta ideia precisa e clara ao explicar o sentido exato em que conhecimento é incompatível com a sorte. De acordo com ele, o tipo de sorte ao qual nós estamos nos referindo ao dizer que o conhecimento não é sortudo é o que ele chama de sorte epistêmica verítica. ${ }^{1}$ Quando a crença de um sujeito, $S$, "sofre de" sorte epistêmica verítica é puramente uma questão de sorte que a sua crença é verdadeira, uma vez que ela tinha tudo para ser falsa.

Essa discussão sobre a incompatibilidade de sorte e conhecimento tem o objetivo principal de explicar o que há de errado com os protagonistas dos casos Gettier os sujeitos gettierizados. O próprio Pritchard (2007) viu aqui uma saída para resolver aquele problema. Ele propôs, anos atrás, uma epistemologia antissorte, isto é, uma epistemologia que tomasse a intuição de que o conhecimento não pode ser sortudo como núcleo para formular uma análise do conhecimento imune ao problema de Gettier. Assim, ele procurou mostrar que a sua epistemologia antissorte poderia ser encarnada por teorias conhecidas na literatura epistemológica - como a teoria da segurança de Ernest Sosa (1999), por exemplo.

Recentemente, contudo, Pritchard admitiu que a epistemologia antissorte não é capaz de explicar todos os casos problemáticos em face dos quais ela é desafiada. E isto é assim porque a epistemologia antissorte não acomoda uma outra intuição igualmente central sobre o conhecimento, a saber, a intuição de que o conhecimento é um produto das habilidades cognitivas do sujeito. Essa intuição é central na epistemologia das virtudes, que explica o conhecimento em termos da agência cognitiva virtuosa (ou habilidosa) do sujeito. Porém, a epistemologia das virtudes também é problemática, pois é pressionada por fortes objeções, como o próprio Pritchard (2012) reconhece. Então, a solução para ele foi propor uma teoria híbrida: uma epistemologia das virtudes antissorte. Supostamente, esta teoria se sai bem onde a epistemologia antissorte e a epistemologia das virtudes fracassam.

Pritchard constata que há duas intuições fundamentais guiando a nossa reflexão sobre o conhecimento: a intuição antissorte e a intuição da habilidade. A intuição antissorte consiste basicamente no seguinte: não é por uma questão de sorte que a crença do sujeito é verdadeira. A intuição da habilidade consiste basicamente no seguinte: se alguém sabe uma proposição, então o seu sucesso cognitivo (isto é, crer em uma verdade) é o resultado do exercício da sua habilidade cognitiva. Muitos aderiram à ideia de que essas duas intuições são, usando as palavras de Pritchard (2012, p.249), "duas faces de uma mesma intuição", tal que quando uma intuição é acomodada por uma teoria, a outra também é. Pritchard pretende mostrar que essa ideia é falsa. Para ele, essas duas intuições impõem exigências independentes sobre o conceito de conhecimento. E é justamente o objetivo dele mostrar que uma epistemologia que reúna essas duas condições adequadamente produz uma análise do conhecimento satisfatória.

Principia 20(2): 179-200 (2016). 
Após expor e avaliar a epistemologia das virtudes antissorte de Pritchard, a nossa proposta é oferecer ao leitor razões para crer que há uma alternativa na literatura mais atrativa para se optar: a teoria da anulabilidade. No que segue, vamos, primeiro, examinar em detalhes as epistemologias antissorte e das virtudes, e vamos mostrar como a epistemologia das virtudes antissorte surge para lidar com os problemas em face dos quais aquelas epistemologias sucumbem. Então, examinaremos a teoria da anulabilidade como uma alternativa à epistemologia das virtudes antissorte, mostrando vantagens teóricas da primeira sobre a última.

\section{A epistemologia antissorte}

A primeira das intuições que Pritchard toma como fundamentais sobre o conhecimento, a já mencionada intuição antissorte, alega que alguém sabe que $P$ somente se não é uma questão de sorte que $P$ é verdadeiro. Esta intuição surge na aurora do problema de Gettier, pois, para muitos, os casos que Gettier apresentou são situações que incitam a intuição de que o sujeito Gettierizado não tem conhecimento porque é apenas por acidente que ele crê na verdade - como no caso Stopped Clock. Para ilustrar o ponto, vejamos mais dois exemplos de gettierização e como a intuição antissorte os explica. Vejamos os casos Lamborghini, inspirado no famoso caso Mr. Nogot de Keith Lehrer (1965), e Fake Barns, apresentado por Alvin Goldman em (1976):

Um dos estudantes da Dra. Lamb, Linus, diz a ela que ele possui um Lamborghini. Linus tem a nota em mãos. A Dra. Lamb viu Linus chegar ao campus no Lamborghini todos os dias dessa semana. Linus, ainda por cima, entregou as chaves à Dra. Lamb e a deixou dar uma volta. A Dra. Lamb crê que Q ' $\mathrm{Li}$ nus possui um Lamborghini', e como um resultado disso conclui $P$ 'Pelo menos um dos meus alunos possui um Lamborghini'. Na realidade, Linus não possui um Lamborghini. Ele está usando o carro emprestado de seu primo, que de fato tem o seu mesmo nome e data de aniversário. Contudo, a Dra. Lamb não tem evidência alguma sobre essa farsa. Todavia, ainda é verdadeiro que pelo menos um de seus alunos possui um Lamborghini: uma moça discreta, que senta no fundo da sala, é dona de um. Mas ela não gosta de se exibir, então ela não chama atenção para o fato de que ela possui um Lamborghini.

$S$ encontra-se no Distrito dos Celeiros Falsos, mas ele não suspeita disso. Todos os celeiros na vizinhança são falsos, exceto o celeiro para o qual $S$ está olhando. Uma vez que este celeiro genuíno e aqueles falsos são indistinguíveis da perspectiva de $S$ e que $S$ não tem qualquer base para pensar que alguma coisa está errada, ele passa a crer veraz e justificadamente que há um celeiro. (Klein 2012, p.159).

Em ambos os casos, a intuição da maioria dos epistemólogos é de que os protagonistas não têm conhecimento das suas crenças-alvo - a saber, 'Pelo menos um

Principia 20(2): 179-200 (2016). 
dos meus alunos possui um Lamborghini' e algo como 'Há um celeiro na minha frente'. Além disso, esses exemplos parecem ratificar a intuição antissorte sobre o conhecimento. No caso Lamborghini, é por pura sorte que a Dra. Lamb acaba crendo em uma verdade; afinal, ela tinha tudo para crer falsamente, não fosse a sorte de haver uma aluna na sua turma que, sem que a Dra. Lamb faça ideia, também possui um Lamborghini. No caso Fake Barns, é igualmente por pura sorte que $S$ acaba crendo na verdade; afinal, ele facilmente acreditaria numa falsidade naquele ambiente enganador, como ele o fez quando olhou para todos os outros celeiros falsos do distrito.

Inspirado na fala de Unger sobre a correta análise do conhecimento, a sugestão de Pritchard é que uma condição que impeça o alcance sortudo (ou acidental) da verdade deve ser imposta sobre qualquer crença candidata a item de conhecimento. A questão que imediatamente se coloca é a seguinte: Que tipo de condição poderia acomodar essa intuição antissorte? Pritchard (2014, p.156) acredita que a condição mais adequada para acomodar a intuição antissorte é o assim chamado princípio de segurança, proposto originalmente por Sosa (1999) e assumido por Williamson (2000), dentre outros.

Segurança: Se $S$ sabe que $P$, então a crença verdadeira de $S$ de que $P$ não poderia facilmente ter sido falsa.

Referindo-se à ideia básica por detrás da condição de segurança, Pritchard (2014, p.156) a qualifica do seguinte modo:

Isso é tipicamente entendido como a alegação de que alguém tem uma crença verdadeira de que $P$ tal que, nos mundos possíveis próximos, se esse alguém continua formando uma crença sobre a mesma base como no mundo atual, então a sua crença continua sendo verdadeira. ${ }^{2}$

O teste do princípio de segurança é bastante simples. Primeiro, considere a crença-alvo do sujeito e o modo como ele a formou. Em seguida, imagine os mundos possíveis próximos - as situações contrafactuais nas quais há pouca variação em relação à situação atual — nos quais o sujeito forma uma crença por meio da mesma base como no mundo atual. Então, basta verificar se nesses mundos o sujeito acaba crendo verazmente. ${ }^{3}$

No caso Lamborghini, há um mundo muito próximo em que ninguém na turma da Dra. Lamb possui um Lamborghini, mundo este que é tal que se ela crê que pelo menos um dos seus alunos possui um Lamborghini, ela crê falsamente e, portanto, não satisfaz a condição de segurança. Do mesmo modo, no caso Fake Barns, há um mundo muito próximo em que não há nenhum celeiro genuíno sequer no distrito, mundo este que é tal que se $S$ crê que ele vê um celeiro (por meio da mesma base sobre a qual ele crê no mundo atual — isto é, via percepção), ele crê falsamente e, portanto, não satisfaz a condição de segurança.

Principia 20(2): 179-200 (2016). 
É possível ver que a condição de segurança acomoda a intuição antissorte, pois se a condição de segurança é satisfeita, então não parece ser uma questão de sorte que o sujeito crê na verdade. Tudo indica que o princípio de segurança dá conta dos casos Gettier, pois os julga como sendo casos de crença insegura e, portanto, casos de ignorância. Porém, os seguintes casos, Temp e Alvin, desafiam esta conclusão. Consideremo-los:

Temp forma as suas crenças sobre a temperatura na sala consultando um termômetro. As suas crenças assim formadas são altamente confiáveis, visto que qualquer crença que ele formar por meio desta base será sempre correta. Além disso, ele não tem razão alguma para pensar que há algo de errado com esse termômetro. Mas o termômetro está quebrado e está oscilando aleatoriamente dentro de uma certa extensão. Sem que Temp o saiba, há um agente escondido na sala, o qual está controlando o termostato e cujo trabalho é garantir que toda vez que Temp consultar o termômetro, o termômetro mostrará a temperatura que corresponde à temperatura da sala. (Pritchard 2012, p.260).

Alvin tem uma lesão cerebral. Um curioso fato sobre a lesão cerebral que Alvin tem é que ela faz com que o paciente forme a crença (verdadeira) de que ele tem uma lesão cerebral. Consequentemente, Alvin crê verazmente que ele tem uma lesão cerebral. (Pritchard 2012, p.263).

Embora (i) Temp acabe com crença verdadeira justificada nesse mundo e nos mundos próximos em que ele forma crenças sobre a temperatura da sala por meio daquela mesma base, ${ }^{4}$ (ii) embora ele não se encontre em um ambiente sortudo, como $S$, no caso Fake Barns, se encontra - pois a verdade da sua crença, longe de ser um acidente, está garantida pelas ações do agente escondido - e (iii) embora ele tenha boa justificação perceptual para crer que a temperatura que ele vê o termômetro marcar é a temperatura correta, ainda assim, Temp não parece ter conhecimento. Intuitivamente, há algo de errado com o modo por meio do qual as suas crenças são tornadas verdadeiras, por mais estável e seguro que seja o método empregado naquele ambiente (a saber, crer no que o relógio mostra estando sob a vigilância do agente escondido).

A sugestão de Pritchard é que a crença-alvo de Temp não se parece com o que esperaríamos de um item de conhecimento, pois o alcance da verdade da sua crençaalvo não é um produto (não resulta da atividade) das suas habilidades cognitivas. Antes, o fato mais saliente na explicação de por que ele acaba crendo na verdade é a ação do agente escondido. Veja o que Pritchard (2012, p.260) tem a dizer sobre por que Temp não parece contar como um caso de conhecimento:

Particularmente, o que há de errado com as crenças de Temp é que elas exibem a direção errada de ajuste com os fatos, pois enquanto a verdade das suas crenças formadas sobre esta base está garantida, a veracidade delas não

Principia 20(2): 179-200 (2016). 
tem nada a ver com as habilidades de Temp, mas tem tudo a ver com algum aspecto externo à agência cognitiva dele.

Pritchard usa este caso para evocar a segunda intuição sobre o conhecimento, a saber, a intuição da habilidade, segundo a qual $S$ sabe que $P$ somente se o seu sucesso cognitivo (isto é, crer em uma verdade) é o resultado do exercício da sua habilidade cognitiva. De acordo com Pritchard, o que está por detrás da nossa intuição de que Temp não tem conhecimento é o fato de que as crenças de Temp não satisfazem a condição da habilidade, isto é, elas não são produtos do exercício das habilidades cognitivas de Temp.

No caso Alvin, o mesmo raciocínio é aplicado. Embora (i) Alvin acabe com crença verdadeira justificada ${ }^{5}$ neste mundo e nos mundos próximos em que ele forma crenças sobre a sua lesão cognitiva por meio daquela mesma base, ${ }^{6}$ (ii) embora ele não se encontre em um ambiente sortudo, pois a verdade da crença sobre a lesão cerebral está garantida pela própria lesão cerebral da qual ele sofre, e (iii) embora ele tenha crença justificada (de um ponto de vista externalista), ainda assim, Alvin não parece ter conhecimento. Intuitivamente, há algo de errado com o modo por meio do qual as suas crenças são tornadas verdadeiras. A crença-alvo de Alvin não se parece com o que esperaríamos de um item de conhecimento. Uma explicação possível é que o alcance da verdade da sua crença-alvo não é um produto (não resulta da atividade) das suas habilidades cognitivas. As crenças de Alvin sobre a sua lesão cerebral são verdadeiras apesar das suas habilidades cognitivas, e não por causa delas.

Note que o princípio de segurança que encarna a intuição antissorte não parece ser capaz de encarnar também a intuição da habilidade - ao menos enquanto os casos Temp e Alvin são a preocupação. A intuição de muitos é de que Temp e Alvin estão Gettierizados. ${ }^{7}$ Mas desta vez, diferentemente das situações exemplificadas nos demais casos Gettier que consideramos, o defeito não tem a ver com sorte. As cenas estão montadas para garantir que a condição de segurança seja satisfeita. Pois nos mundos próximos nos quais Temp formar crenças consultando o termômetro, ele crerá verazmente, pois o agente escondido fará com que o termômetro mostre a real temperatura da sala.

A lição que Pritchard quer que tomemos é a seguinte: o fato do sucesso cognitivo de Temp não ser um produto do exercício das suas habilidades cognitivas não se deve à presença de sorte epistêmica; portanto, a epistemologia antissorte não é capaz de explicar todos os casos de gettierização. E o mesmo raciocínio se aplica a Alvin. Visto que Alvin satisfaz a condição de segurança, a melhor explicação para a intuição de que as crenças dele não constituem itens de conhecimento é que elas não satisfazem a condição da habilidade - mais uma vez, condição esta que a epistemologia antissorte não acomoda.

Portanto, ou (i) desabusamos Pritchard das suas intuições quanto aos casos Temp 
e Alvin, ou (ii) concedemos a ele o ponto de que a intuição antissorte encarnada no princípio de segurança não dá conta de todos os casos Gettier e, assim, não é capaz de oferecer uma análise satisfatória do conhecimento.

O segundo passo no argumento de Pritchard pede que façamos agora o caminho inverso. Consideraremos a hipótese de que a intuição mais básica sobre o conhecimento é a intuição da habilidade e que uma epistemologia das virtudes é a candidata mais adequada para encarnar uma intuição da habilidade que acomode ao mesmo tempo a intuição antissorte. Veremos, ao final da próxima seção, se esta proposta é bem-sucedida ou fracassada.

\section{A epistemologia das virtudes}

A epistemologia das virtudes marca uma mudança na direção da análise do conhecimento. Tradicionalmente, as crenças eram os itens que portavam as propriedades relevantes para a avaliação epistêmica (exceto a verdade, que é uma propriedade da proposição). Isto significa que para julgarmos se um sujeito possuía conhecimento de que $P$, verificávamos as propriedades da crença em $P$ deste sujeito - tais como ser baseada em boas razões ou ser produzida por um processo confiável de formação de crenças. Na epistemologia das virtudes, o sujeito (ou agente) passa a ser o foco da avaliação epistêmica. Nesta nova perspectiva, para julgarmos se um sujeito possui conhecimento de que $P$, verificaremos as propriedades que este sujeito exibe ao crer que $P$ - tais como empregar faculdades cognitivas confiáveis ou exibir traços de caráter relevantes ao formar a crença em $P$.

Pritchard sugere que façamos uma distinção entre dois tipos de epistemologia das virtudes, a qual se mostrará útil mais adiante. A primeira delas é o que ele chama de epistemologia das virtudes fraca. A condição da habilidade que a epistemologia das virtudes fraca produz poderia ser como a seguinte: $S$ sabe que $P$ somente se o seu sucesso cognitivo em relação a $P$ (isto é, crer verazmente que $P$ ) é o produto do exercício das suas habilidades cognitivas. Em outras palavras, a crença de $S$ de que $P$ é conhecimento só se a crença verdadeira de $S$ em $P$ é o resultado do emprego de certas habilidades cognitivas ao formar aquela crença. Se você crê que está chovendo com base na sua percepção da chuva lá fora, a sua crença pode ser um caso de conhecimento, pois é o produto da sua habilidade cognitiva perceptual. Se você crê que a sua irmã não está em casa com base na crença de que hoje é o dia em que ela faz natação e ela não mencionou qualquer mudança na agenda, então a sua crença pode ser um caso de conhecimento, pois é o produto da sua habilidade cognitiva inferencial.

Note que a intuição por detrás desta condição de habilidade é capaz de explicar por que nem Temp nem Alvin tem conhecimento: o sucesso cognitivo de Temp e o sucesso cognitivo de Alvin quanto ao alcance da verdade não são produtos do exer-

Principia 20(2): 179-200 (2016). 
cício das habilidades cognitivas deles. No caso de Temp, a verdade da crença-alvo tem a ver com a ação do agente escondido, não com a sua consulta ao termômetro, pois este está quebrado; a crença de que o termômetro marca uma determinada temperatura não é produto do exercício das habilidades cognitivas de Temp, mas sim produto da manipulação do agente escondido. No caso de Alvin, ele nem sequer está exercitando uma habilidade cognitiva. A crença-alvo de Alvin não é produto da sua habilidade cognitiva, mas sim produto da sua deficiência cognitiva.

No entanto, os casos Gettier que a epistemologia antissorte dava conta são agora um problema para esta epistemologia das virtudes fraca. Pois considere novamente o caso Lamborghini, por exemplo. Lá, o fato de a Dra. Lamb crer na verdade de que pelo menos um dos seus alunos possui um Lamborghini é, pelo menos em um aspecto importante, o produto do exercício de uma das suas habilidades cognitivas, a saber, o raciocínio. Uma das explicações de por que ela acaba com crença verdadeira é que ela raciocina validamente da premissa sobre Linus à conclusão da crença-alvo - aplicando uma regra de derivação válida. No caso Fake Barns, a dificuldade para a epistemologia das virtudes fraca fica ainda mais evidente. Lá, o fato de $S$ crer na verdade de que há um celeiro na frente dele deve-se ao exercício de uma das suas habilidades cognitivas, a saber, a percepção. A explicação de por que ele acaba com crença verdadeira é que ele está vendo um celeiro na sua frente.

Aqui, uma distinção importante precisa ser marcada (Cf. Grego 2012a, p.3), a saber, a distinção entre (i) uma crença que é verdadeira $e$ que é produzida pelas habilidades cognitivas do sujeito, e (ii) uma crença que é verdadeira porque é produzida pelas habilidades cognitivas do sujeito. O problema é que a condição da habilidade sugerida pela epistemologia das virtudes fraca pode ser lida como o que está expresso pela relação (i), ao passo que (ii) parece ser a relação necessária para a posse de conhecimento. Tudo indica que a relação explicativa entre a crença verdadeira e as habilidades cognitivas precisa ser mais forte que aquela oferecida pela epistemologia das virtudes fraca.

O segundo tipo de epistemologia das virtudes vem para ser bem-sucedido onde a alternativa anterior fracassa. Na tentativa de tornar a relação explicativa mais forte e competente para lidar com os casos Gettier, bem como com os casos Temp e Alvin, surge a epistemologia das virtudes forte. A condição da habilidade que esta epistemologia produz é a seguinte: $S$ sabe que $P$ somente se $S$ crê verazmente que $P$ por causa do exercício das suas habilidades cognitivas. Aqui, a explicação sobre por que o caso Lamborghini não é um caso de conhecimento é que a Dra. Lamb não chega à verdade sobre um de seus alunos possuir um Lamborghini por causa do seu raciocínio hábil, mas sim por causa da presença da aluna discreta em sua turma, a qual ela não faz ideia que possui um Lamborghini. O seguinte excerto de John Greco (2012a, pp.89) ajuda-nos a explicar em que sentido, exatamente, $S$ crê verazmente por causa do exercício das suas habilidades cognitivas:

Principia 20(2): 179-200 (2016). 
A ideia é que, nos casos de conhecimento, a competência de $S$ explica por que $S$ tem uma crença verdadeira, em vez de uma crença falsa, ou nenhuma crença sequer. Nos casos Gettier, alguma outra coisa explica por que $S$ tem uma crença verdadeira.

A leitura forte da relação explicativa entre o sucesso cognitivo e as habilidades cognitivas do sujeito permite à condição de habilidade lidar adequadamente com os casos Gettier. No caso Lamborghini, como dissemos anteriormente, a crença-alvo da Dra. Lamb não se deve em primeiro lugar à sua habilidade cognitiva, mas sim à feliz coincidência de que um dos seus alunos, que não o farsante Linus, possui uma Lamborghini. O exercício das habilidades cognitivas da Dra. Lamb não é o fator mais importante na explicação para o seu sucesso cognitivo; é a presença da aluna discreta o que explica por que a Dra. Lamb tem uma crença verdadeira. No paradigmático caso Gettier Stopped Clock, a mesma situação se dá: embora a crença-alvo de $S$ seja produto do exercício da sua percepção, o fator mais importante na explicação para o seu sucesso cognitivo é o evento fortuito do relógio que não está funcionando ter parado há exatamente 12 horas.

Todavia, note que o caso Fake Barns ainda é um problema para a explicação da epistemologia das virtudes forte. Afinal, neste caso, é exatamente por causa da percepção hábil de $S$ que ele crê verazmente que há um celeiro na sua frente. Nos demais casos Gettier, a causa mais importante do sucesso cognitivo do sujeito tem a ver com algum fato sobre o qual ele não faz ideia. Porém, no caso Fake Barns, o fator mais importante na explicação causal do sucesso cognitivo do sujeito tem a ver justamente com aquilo que o faz alcançar uma crença verdadeira, a saber, o exercício da sua percepção hábil; $S$ crê verazmente por causa do exercício das suas habilidades cognitivas. Portanto, a epistemologia das virtudes forte precisa dar uma explicação sobre este caso.

Há modos de resistir e responder à objeção recém exposta. Ernest Sosa (2007, capítulo 5), por exemplo, resiste à objeção ao tomar o caso Fake Barns como um caso de conhecimento. Para Sosa, uma vez que $S$ é bem-sucedido porque é competente (isto é, porque exercitou suas habilidades cognitivas adequadamente), é plausível tomá-lo como sabedor, não obstante o ambiente em que ele se encontra. Porém, esta é uma posição impopular, pois é contraintuitiva para a maioria dos epistemólogos. Já um modo de responder à objeção seria, por exemplo, trazer à tona a suposição de que habilidades devem ser relativizadas aos ambientes nos quais são exercidas. Seguindo este raciocínio, somos convidados a pensar que as condições para o exercício da percepção hábil no ambiente em que $S$ se encontra no caso Fake Barns são muito mais exigentes que em ambientes normais. No ambiente daquele caso, para perceber habilmente que há um celeiro, $S$ deve ser capaz de discriminar os celeiros genuínos dos falsos, e uma vez que $S$ é incapaz de fazê-lo, conclui-se que $S$ não crê na verdade por meio das suas habilidades cognitivas pois não é capaz de exercê-las, e essa é a razão 
pela qual não estamos dispostos a atribuir conhecimento a ele. Todavia, ambas essas linhas de defesa são objetadas na literatura, o que mostra não haver condições de tratar o problema como apenas periférico. ${ }^{8} \mathrm{~A}$ epistemologia das virtudes forte ainda é muito fraca. Portanto, o caso Fake Barns pede por uma condição de habilidade mais forte. E ao que parece, este não é o único dos problemas para a epistemologia das virtudes forte. Ela também padece ao explicar casos de conhecimento via testemunho. Considere o caso Chicago Visitor, originalmente proposto por Jennifer Lackey (2007):

Tendo recém chegado à estação de trem em Chicago, Morris deseja conseguir o endereço para chegar à Sears Tower. Ele olha ao seu redor, aleatoriamente aborda o primeiro transeunte que ele vê, e pergunta como chegar ao seu destino desejado. O transeunte, que por acaso é um morador de Chicago que conhece a cidade extraordinariamente bem, dá a Morris impecáveis direções à Sears Tower. (Greco 2012, p.4).

A maioria dos epistemólogos considera este caso um típico exemplo de conhecimento testemunhal. Porém, neste caso, nós diríamos que o sucesso do sujeito em crer na verdade é atribuído às habilidades dele? Possivelmente, muitos diriam que não. O "trabalho intelectual", por assim dizer, a que se atribui o alcance da verdade da crença-alvo é todo feito pelo transeunte. Foi ele quem, de algum modo, exercitou as suas habilidades intelectuais para ganhar a informação verdadeira sobre a localização da Sears Tower, passando em frente ao prédio e lendo a placa com o seu nome, por exemplo. Morris simplesmente escolheu um desconhecido aleatoriamente. Como Pritchard (2012, p.270) reconhece, ninguém nega que o sucesso cognitivo de Morris se deve ao menos em parte ao exercício das suas habilidades cognitivas. Porém, o objetor diria que claramente o fator mais importante na explicação causal do sucesso cognitivo de Morris não é o exercício das suas habilidades cognitivas, mas o exercício das habilidades cognitivas da testemunha. O problema é que, como dissemos, o caso Chicago Visitor é tomado pela maioria dos epistemólogos como um caso de conhecimento. Mas, como estamos argumento, a epistemologia das virtudes forte não acomoda adequadamente esta intuição. Pressionada por esta objeção, a epistemologia das virtudes forte parece ser forte demais. Portanto, o caso Chicago Visitor pede por uma condição de habilidade mais fraca.

Não será uma saída para o epistemólogo da virtude dizer que Morris ganha uma crença verdadeira tanto por meio dos seus esforços intelectuais quanto por meio dos esforços intelectuais da testemunha, de tal maneira que o importante é que $S$ tenha seu sucesso atribuído ao menos em parte às suas habilidades. Como Lackey (2009, p.34) observou, isso traria problemas para o tratamento dos casos Gettier. Como vimos anteriormente, naqueles casos, $S$ também tem o seu sucesso atribuído ao menos em parte às suas habilidades. No caso Lamborghini, por exemplo, embora 
o sucesso da crença-alvo seja explicado pela presença da aluna discreta na turma, o fato de que a Dra. Lamb crê verazmente também é explicado ao menos em parte pela sua competência em raciocinar validamente. Ela aplica competentemente uma regra de derivação válida a uma crença justificada sobre Linus.

Estas considerações remetem-nos ao aspecto mais complexo da explicação da epistemologia das virtudes forte, a saber, como devemos entender a relação de atribuição do sucesso cognitivo ao exercício das habilidades pelo sujeito. John Greco (2012a, p.4), comentando Jennifer Lackey, mostra precisamente qual é o problema aqui. Ele o vê como um dilema, com as seguintes opções: ou (i) faz-se a relação de atribuição mais forte, de modo que ela exclua os casos de gettierização, ou (ii) faz-se a relação de atribuição mais fraca, de modo que ela acomode os casos de conhecimento testemunhal. Porém, com (i), perde-se a capacidade de dar conta dos casos de conhecimento testemunhal, e com (ii), perde-se a capacidade de dar conta dos casos de gettierização. Em suma, o ponto é que qualquer teoria sobre a relação de atribuição precisará fazer as nossas intuições sobre os casos Gettier e sobre o conhecimento via testemunho compatíveis, o que se mostra uma tarefa difícil. ${ }^{9}$

Por tudo o que foi dito, é possível ter dimensão da dificuldade que a epistemologia das virtudes forte enfrenta no cenário atual. Além de precisar vender-nos noções não epistêmicas - como 'habilidade' e 'sucesso' - suas respectivas analogias em epistemologia, e uma teoria sobre a relação de atribuição, ela ainda precisa dar conta dos problemas recém expostos.

\section{A epistemologia das virtudes antissorte}

Tendo em vista os problemas enfrentados pela epistemologia antissorte e pela epistemologia das virtudes, Pritchard sugere que a melhor opção a ser tomada é adotar uma teoria híbrida: uma epistemologia das virtudes antissorte. Esta teoria, segundo ele, sintetiza as condições que cada uma daquelas epistemologias oferece individualmente. Lembre-se que a hipótese era que satisfazendo uma delas, a outra também seria satisfeita. Para Pritchard, este é justamente o erro daqueles dois projetos. A intuição antissorte e a intuição da habilidade impõem exigências distintas e independentes sobre o conhecimento. A nova teoria de Pritchard (2012, p.273) é expressa como segue:

Epistemologia das virtudes antissorte: $S$ sabe que $P$ se e somente se a crença verdadeira e segura de que $P$ é o produto das habilidades cognitivas relevantes de $S$ (tal que o seu sucesso cognitivo seguro é significativamente creditável à sua agência cognitiva).

A expectativa é que esta teoria dê conta de todos os casos problemáticos. Um tratamento dos casos à luz da análise oferecida verifica isto. Consideremos os desafios 
que esta nova proposta de Pritchard vai enfrentar. Em primeiro lugar, ela precisa ser tão eficiente quanto suas competidoras no que diz respeito ao tratamento dos casos Gettier clássicos, tais como Stopped Clock e Lamborghini. Aqui, a exigência por segurança presente na análise de Pritchard é suficiente para explicar o que há de errado naqueles casos. Ambos os casos Stopped Clock e Lamborghini são casos de crença insegura. Facilmente a crença-alvo de $S$ de que são cinco horas teria sido falsa se fosse formada por meio da consulta a um relógio parado; em qualquer outro momento do dia o sujeito acreditaria falsamente que são cinco horas ao consultar aquele relógio. Do mesmo modo, facilmente a crença-alvo da Dra. Lamb de que pelo menos um dos seus alunos possui um Lamborghini teria sido falsa se fosse formada pelo testemunho de Linus em circunstâncias similares; se a moça discreta não se matriculasse naquela turma, a Dra. Lamb acabaria com uma crença falsa.

Em segundo lugar, a proposta de Pritchard precisa acomodar as seguintes demandas, aparentemente incompatíveis: ela precisa ser mais forte que a epistemologia das virtudes forte para tomar o caso Fake Barns como um caso de ignorância, e mais fraca que a epistemologia das virtudes forte para tomar o caso Chicago Visitor como um caso de conhecimento. Considerando o caso Fake Barns, novamente a exigência por segurança presente na análise de Pritchard é suficiente para explicar o que há de errado. Afinal a crença de $S$ de que há um celeiro na sua frente não é segura; ela facilmente teria sido falsa se fosse formada em situações similares à situação atual. Nos mundos mais próximos em que $S$ forma uma crença sobre a presença de um celeiro na sua frente do mesmo modo como no mundo atual, a crença de $S$ acaba sendo falsa; esses mundos estão repletos de celeiros falsos. A condição antissorte presente na análise de Pritchard permite-nos, assim, julgar que $S$, no mundo atual, não sabe que há um celeiro na sua frente.

Considerando o caso Chicago Visitor, devemos nos voltar para a exigência segundo à qual o sucesso cognitivo de $S$ deve ser significativamente creditável à agência cognitiva de $S$. É verdade que o fator mais importante na explicação causal do sucesso cognitivo de Morris não é o exercício das suas habilidades cognitivas, mas sim o exercício das habilidades cognitivas da testemunha. No entanto, como dissemos anteriormente, Morris está exibindo habilidades cognitivas ao crer verazmente via testemunho, a saber, habilidades relevantes para aquisição de conhecimento testemunhal. Morris confia na palavra da testemunha, mas não o faz acriticamente.

Embora Morris pergunte pela direção para a Sears Tower à primeira pessoa que encontra na rua, ele certamente observa esta pessoa razoavelmente a fim de encontrar indícios relevantes à confiabilidade do seu testemunho e à verdade da proposição testemunhada; indícios de honestidade, de condições de informar sobre aquele assunto, e até mesmo indícios de sanidade mental. Se a testemunha aparentasse não estar muito certa sobre o que está prestes a dizer, ou aparentasse ser um turista desinformado, ou ainda um ladrão que poderia aproveitar a ocasião para lhe preparar 
uma emboscada, então Morris provavelmente não consideraria aquele testemunho e procuraria por outro. Além disso, é plausível supor que Morris monitora epistemicamente o testemunho; afinal, Morris o toma em vista das suas crenças de fundo sobre o que pareceria uma resposta razoável ao seu pedido por informação. Se a testemunha dissesse a ele algo completamente inconsistente com as suas crenças prévias sobre aspectos da localização da Sears Tower, ele não tomaria o testemunho como relevante. Portanto, visto todas essas posturas de Morris ao acreditar no testemunho que recebe, é razoável pensar que o seu sucesso cognitivo é significativamente creditável à sua agência cognitiva. Notemos ainda que a crença de Morris é segura, pois nos mundos possíveis próximos em que é formada como no mundo atual, ela segue sendo verdadeira - pois nestes mundos próximos não há complôs para enganar Morris e os transeuntes não costumam ser pessoas mentirosas, por exemplo. Assim, a crença segura de Morris que é produto das suas habilidades cognitivas é propriamente contada como um caso de conhecimento.

Por fim, os casos Temp e Alvin também são acomodados pela epistemologia antissorte de Pritchard. Este é, na realidade, um resultado muito simples da teoria. Como vimos ao examinar a epistemologia das virtudes, o sucesso cognitivo de Temp e o sucesso cognitivo de Alvin não são produtos do exercício das habilidades cognitivas deles. O sucesso cognitivo de Temp quanto à temperatura da sala é produto da ação do agente escondido na sala que manipula a situação para que Temp acabe com crença verdadeira. Já o sucesso cognitivo de Alvin não exibe nenhuma habilidade cognitiva sequer; sua crença verdadeira é produto da sua deficiência cognitiva que a causa.

Assim, tudo indica que a epistemologia das virtudes antissorte de Pritchard se sai bem ao lidar com o problema de Gettier e com os casos problemáticos que a epistemologia antissorte e a epistemologia das virtudes enfrentam, sem sucesso, individualmente. A epistemologia das virtudes antissorte coloca-se, assim, como uma análise do conhecimento satisfatória prima facie. Mas esta teoria não reúne apenas as virtudes da epistemologia antissorte e da epistemologia das virtudes; ela também importa as suas dificuldades mais básicas. Na próxima seção, argumentaremos que tais dificuldades básicas inerentes à proposta de Pritchard podem ser evitadas, uma vez que há uma alternativa mais simples no mercado, com igual ou maior poder explicativo.

\section{Uma alternativa: A teoria da Anulabilidade}

O objetivo desta seção é explorar uma alternativa à epistemologia das virtudes antissorte oferecida por Pritchard. Nossa intenção é apresentar ao leitor razões para crer que a explicação anulabilista do conhecimento é mais econômica e ecumênica

Principia 20(2): 179-200 (2016). 
que a proposta de Pritchard, mostrando-se, assim, a melhor teoria para se optar. A teoria da anulabilidade começa explicando por que razão os casos Gettier não contam como casos de conhecimento. Naqueles casos, $S$ alcança a verdade por um acidente (epistemicamente) sortudo. A sorte está no fato de $S$ não ter adquirido uma informação importante sobre a verdade da crença-alvo. ${ }^{10}$ De acordo com a teoria da anulabilidade, há uma informação adicional (isto é, uma proposição verdadeira) não acreditada por $S$ que derrota a sua justificação - o assim chamado derrotador.

O derrotador da justificação de uma crença-alvo $P$ é uma proposição verdadeira que, quando conjugada com a evidência de $S$ para crer que $P$, o faz injustificado em manter essa crença (ou diminui o status justificacional dessa crença para $S$ ). Note que em todo caso Gettier é possível identificar um derrotador para a justificação da crença-alvo do protagonista. No caso Stopped Clock, a proposição verdadeira "O relógio para o qual $S$ está olhando está parado" é um derrotador da justificação de $S$ para crer que $P$, "São cinco horas", pois aquela informação, ao ser conjugada com a evidência perceptual de $S$, o faz injustificado em crer que $P$ (isto é, crer que são cinco horas). No caso Lamborghini, o derrotador é a proposição verdadeira "Linus é um farsante e não possui Lamborghini algum". Se esta informação é adicionada ao sistema doxástico da Dra. Lamb, ela perde a sua justificação para crer que pelo menos um dos seus alunos possui um Lamborghini, pois ela perde justificação para crer na premissa que autoriza esta sua conclusão. No caso Fake Barns, o derrotador é "Este é um distrito repleto de celeiros falsos". Se $S$ é informado sobre isso, ele se torna injustificado em crer que vê um celeiro, pois ele passa a reconhecer a sua incapacidade de discriminar celeiros genuínos de celeiros falsos naquele ambiente. Por fim, no caso Temp, o derrotador é "O termômetro por meio do qual Temp baseia as suas crenças sobre a temperatura está quebrado". Se esta proposição verdadeira é adicionada ao sistema doxástico de Temp, ele se torna injustificado em crer na temperatura que o termômetro mostra, pois a informação de que o termômetro está quebrado contrabalança a justificação perceptual que a consulta ao termômetro inicialmente fornece a ele.

Uma observação importante ainda precisa ser feita para que tenhamos uma teoria da anulabilidade completa. Assim como contraevidências podem ser elas mesmas anuladas por outras contraevidências, cancelando o efeito das primeiras, derrotadores podem ser eles mesmos derrotados. Considere uma adaptação do famoso caso de Lehrer and Paxson (1969), A Louca Sra. Grabit:

Eu vejo um sujeito que me parece ser Tom Grabit roubando um livro na biblioteca. Minha observação do sujeito e do comportamento dele (sob boa iluminação, em uma distância curta, recordando-me de como Tom se parece) não deixa espaço pra dúvida: $(P)$ o ladrão deve ser Tom Grabit. Contudo, sem que eu o saiba, (D) a Sra. Grabit, mãe de Tom, testemunha que, enquanto Tom estava viajando, o irmão gêmeo dele estava na biblioteca no dia em questão. No

Principia 20(2): 179-200 (2016). 
entanto, também sem que eu o saiba, $(R)$ a Sra. Grabit sofre de Alzheimer e está fazendo uma alegação falsa sobre um gêmeo que sequer existe. Foi de fato Tom quem roubou o livro.

Ao lidar com este caso, Klein (1981) sugere a introdução de uma distinção entre derrotadores. Há dois tipos: o derrotador genuíno e o derrotador enganador. O derrotador genuíno derrota através da verdade - este é o tipo de derrotador presente nos casos de gettierização. $O$ derrotador enganador derrota apenas através da falsidade. Neste caso, a proposição verdadeira $D$, sobre o testemunho da mãe de Tom, é um derrotador enganador, pois derrota apenas porque faz a falsidade $F$ plausível para mim, a saber, "Quem roubou o livro foi o irmão de Tom". Aqui, a proposição $D$ é o que chamamos de derrotador inicial e $F$ é o que chamamos de derrotador efetivo - o primeiro e o último elo da cadeia inferencial derrotadora, respectivamente. O ponto é que todo o efeito destrutivo que o derrotador inicial enganador causa é cancelado pela proposição $R$ - o restaurador da justificação original — tal que derrotadores enganadores não impedem a posse de conhecimento; apenas os derrotadores genuínos o fazem.

Assim, a análise anulabilista é propriamente expressa do seguinte modo: $S$ sabe que $P$ se e somente se (i) $P$, (ii) $S$ crê que $P$, (iii) $S$ crê justificadamente que $P$, e (iv) não há qualquer derrotador genuíno da justificação para $P$. As condições (i), (ii) e (iii) se mantém no espírito do que Gettier tomou como sendo a análise clássica do conhecimento. A condição (iv) é propriamente a condição anulabilista, que explica a presença de conhecimento nos bons casos, a ausência dele nos casos de gettierização, e os resultados intuitivamente desejáveis em casos mais complexos, como A Louca Sra. Grabit.

Há, neste ponto, uma observação de esclarecimento importante sobre possíveis implicações problemáticas da teoria da anulabilidade. Esta observação diz respeito à caracterização dos derrotadores, tal como a apresentamos acima. Recentemente, John Turri (2012, pp.218-219), ao revisar a literatura sobre o problema de Gettier, avaliando a qualidade das tentativas de solução que surgiram ao longo dos últimos cinquenta anos, considerou a teoria da anulabilidade fracassada. O problema, segundo Turri, consiste no fato de que a introdução da distinção entre derrotadores genuínos e enganadores, bem como a introdução do chamado restaurador, embora dê conta do caso A Louca Sra. Grabit, faz com que a teoria passe a julgar os casos Gettier como casos de conhecimento. Considere a estrutura do caso Lamborghini:

$(E)$ : Linus diz à Dra. Lamb que ele possui um Lamborghini; Linus tem a nota em mãos; a Dra. Lamb viu Linus chegar ao campus no Lamborghini todos os dias dessa semana; Linus entregou as chaves à Dra. Lamb e a deixou dar uma volta.

$(P)$ : Pelo menos um dos meus alunos possui um Lamborghini.

$(D)$ : Linus não possui um Lamborghini.

Principia 20(2): 179-200 (2016). 
$(R)$ : Uma moça discreta, que senta no fundo da sala, possui um Lamborghini.

Note que, embora a conjunção $(D \& E)$ não mais justifique $P$ para a Dra. Lamb, se uma outra verdade relevante na "vizinhança", a saber, $R$, é adicionada ao seu sistema doxástico, a conjunção $(D \& E \& R)$ volta a justificar $P$ para ela. E isso é assim com todo caso Gettier, uma vez que a crença gettierizada é sempre verdadeira, e sempre haverá alguma proposição capaz de justificá-la. Sendo assim, basta que encontremos a verdade que explica a verdade da crença gettierizada, a adicionemos ao sistema doxástico do sujeito, e ela contrabalançará o efeito do derrotador. O problema, em outras palavras, é que parece ser possível encontrar um restaurador para todo derrotador.

Mas, o argumento de Turri é falacioso. De acordo com ele, supostamente, a adição de $R$ ao sistema doxástico da Dra. Lamb restaurará a justificação dela para crer que $P$. Mas $R$ não o fará. A justificação que ela mantinha para crer que $P$ não passa a ser boa simplesmente porque há uma aluna na turma, sobre quem ela não sabe nada, que possui um Lamborghini. A justificação original da Dra. Lamb para crer que $P$ depende exclusivamente de $E$, isto é, de toda a evidência enganadora oferecida por Linus. A verdade $R$ não é capaz de restaurar aquela justificação porque aquela justificação é derrotada para além de restauração - como é o caso com toda a justificação para uma crença gettierizada.

De fato, a conjunção $(D \& E \& R)$ volta a justificar $P$ para a Dra. Lamb, mas não porque a sua justificação original, $E$, foi restaurada. Antes, porque $R$, sozinha, é capaz de justificar a crença em $P$ para ela. O que $R$ faz é dar à Dra. Lamb uma nova justificação para crer que $P$. A verdade $R$ é uma criadora de justificação, e não uma restauradora. Não há esperança de restauração para a justificação que $E$ confere a $P$. Há, no máximo, a chance da criação de uma nova justificação. E é exatamente isso - criar uma nova justificação - o que $R$ faz nesse cenário. Portanto, a objeção de Turri à teoria da anulabilidade pode ser descartada, porque a sua interpretação da teoria é incapaz de distinguir quando uma verdade restaura a justificação original do sujeito de quando ela cria uma justificação inteiramente nova para ele. ${ }^{11}$

Há ainda outros desafios à teoria da anulabilidade expressos na literatura. Alguns epistemólogos pressionaram os anulabilistas com casos nos quais as opiniões sobre a posse de conhecimento pelo protagonista divergem - como o famoso caso Newspaper, de Gilbert Harman (1968). Outros acusaram a teoria de implicar um tipo de infalibilismo quanto à justificação boa para o conhecimento - como Linda Zagzebski (2009) e Claudio De Almeida (a ser publicado). Outros, ainda, apontaram dificuldades que a teoria supostamente enfrenta em face dos casos de conhecimento via falsidades - como Klein (2008). No entanto, recentemente, tais objeções foram tratadas em detalhes e respondidas no espírito da teoria da anulabilidade - como em Klein (a ser publicado), De Almeida (a ser publicado), e De Almeida e Fett (2016). Sendo 
assim, acreditamos que a teoria da anulabilidade se coloca como uma boa candidata para contar como uma análise do conhecimento satisfatória. No que segue, exploraremos algumas vantagens teóricas da teoria da anulabilidade sobre a epistemologia das virtudes antissorte.

\section{Uma teoria econômica}

Uma das razões pelas quais a teoria da anulabilidade é preferível à teoria de Pritchard é porque a teoria da anulabilidade é mais econômica, pois não precisa se comprometer com certas teorias robustas e objetáveis (nem importar os seus problemas) para explicar o conhecimento. A teoria da anulabilidade não precisa, por exemplo, de teorias sobre situações contrafactuais para a teorização epistemológica, importando, assim, seus possíveis problemas. A teoria da anulabilidade não precisa se ocupar da difícil tarefa de explicar o que acontece em mundos próximos diferentes do mundo atual, nem da tarefa de oferecer uma teoria sobre a proximidade (ou similaridade) entre mundos - questões que pressionam o princípio de Segurança e a epistemologia antissorte. $^{12}$

Mas mais importante que isso, a teoria da anulabilidade não precisa se ocupar das difíceis questões que concernem à condição da habilidade presente na epistemologia de Pritchard. Para o sucesso daquele empreendimento, é necessário haver uma explicação fundamentada para as seguintes questões: Qual a natureza das virtudes epistêmicas? Sob quais condições o sujeito as exerce?

Para vislumbrarmos possíveis respostas às questões acima, algumas observações precisam ser feitas. O rótulo 'epistemologia das virtudes' compreende uma coletânea de diferentes teses sobre o conhecimento, a justificação, e o tratamento dos problemas epistêmicos. Um dos momentos em que essa diversidade fica evidente é quando se pergunta o que se entende por virtude epistêmica. Não obstante a existência de posições híbridas em certos aspectos, há dois partidos em cena: os confiabilistas e os responsabilistas.

Os confiabilistas, que costumam assumir a agenda tradicional da epistemologia contemporânea, entendem a noção de virtude epistêmica como uma disposição confiável para o alcance de "bens epistêmicos", tais como o conhecimento e a justificação. Virtudes epistêmicas são habilidades ou faculdades cognitivas confiáveis no que diz respeito à produção de crenças justificadas e de itens de conhecimento, como percepção confiável e raciocínio apurado, por exemplo. Os responsabilistas, que costumam assumir uma agenda heterodoxa, entendem a noção de virtude epistêmica analogamente à noção de virtude moral, isto é, como traços de caráter, como mente aberta e conscienciosidade intelectual. A disputa entre os partidos é acirrada, e escolher um em detrimento de outro tem o ônus de dar conta de objeções.

Além disso, alertados pela objeção de Jennifer Lackey à epistemologia das virtu-

Principia 20(2): 179-200 (2016). 
des, notamos que não é uma tarefa fácil explicar a natureza da relação de atribuição do sucesso de crer verazmente ao exercício das habilidades cognitivas do sujeito. Há, na literatura, muitos modos de se entender a relação de atribuição. Dois deles são os mais populares. Vamos examiná-los no que segue.

Alguns sugerem que a relação de atribuição é explicativa. Sosa (2007), neste sentido, propôs que um sucesso é atribuível a um sujeito se e somente se este sucesso é causalmente explicado pela competência deste sujeito. John Greco (2010, capítulo 5) propôs algo semelhante: um sucesso é atribuível a um sujeito se e somente se este sucesso é explicável pelo exercício das suas habilidades - isto é, o exercício competente das habilidades cognitivas do sujeito explica por que ele crê verazmente. Porém, se a natureza da relação de atribuição é explicativa, uma série de questões sobre estrutura causal e sobre como a saliência explicativa se distribui precisam ser igualmente respondidas. Ambas as propostas de Sosa (2007) e Greco (2010) são pressionadas por fortes objeções na literatura, como mostra o próprio Greco (2012a, pp.8-12).

Alguns sugerem que a natureza da relação de atribuição é metafísica. John Turri (2011), por exemplo, sugere uma teoria neste espírito. De acordo com ele, um sucesso é atribuível a um sujeito se e somente se este sucesso manifesta a competência deste sujeito. Ernest Sosa (2010), em outra ocasião, oferece uma teoria muito semelhante à teoria de Turri. De acordo com ele, um sucesso é atribuível a um sujeito se e somente se este sucesso manifesta caracteristicamente a competência deste sujeito. Porém, se a natureza da relação de atribuição é metafísica e uma teoria como a de Turri ou como a de Sosa está correta, questões sobre que tipo de coisa é a relação de manifestação de uma competência por um sujeito precisam ser respondidas. A sugestão de Turri, que a toma como primitiva, é objetável, como mostra Greco (2012a, pp.8-12). A resposta de Sosa é evasiva. Ele sugere que se deixe a questão sobre o que é a manifestação característica de uma disposição para os metafísicos responderem. ${ }^{13}$

Nós estamos oferecendo uma alternativa mais barata e eficaz aqui. Para explicar o conhecimento, nós não precisamos das noções de sucesso, habilidade e virtude, nem precisamos oferecer qualquer explicação sobre a relação de atribuição do sucesso de crer verazmente às habilidades cognitivas do sujeito. A teoria da anulabilidade explica o conhecimento em termos puramente epistêmicos.

\section{Uma teoria ecumênica}

Outra das razões pelas quais a teoria da anulabilidade é preferível à teoria de Pritchard é que a teoria da anulabilidade é mais ecumênica, no sentido de que mantém neutralidade quanto ao debate internalismo vs. externalismo.

Tanto a epistemologia antissorte quanto a epistemologias das virtudes são epistemologias incapazes de acomodar intuições internalistas sobre justificação epistêmica 
e, por consequência, sobre o conhecimento. Elas são paradigmaticamente externalistas, pois implicam que justificação epistêmica não precisa desempenhar qualquer papel para a aquisição de conhecimento e que o sujeito não precisa estar justificado para que ele o possua; basta que a sua crença seja modalmente segura ou produzida pelas suas habilidades cognitivas. Internalistas, como Feldman e Conee (2004, p.3), por sua vez, sustentam que justificação epistêmica é "uma condição necessária importante para o conhecimento". Não é possível para internalistas que a justificação epistêmica seja irrelevante para a posse de conhecimento. Eis a incompatibilidade com o primeiro aspecto da proposta de Pritchard.

Poderia ser objetado que embora a condição antissorte, encarnada pelo princípio de segurança, frustre intuições internalistas, a condição da habilidade as acomoda, como Pritchard (2012) procurou mostrar. Porém, isto não parece ser o caso. A epistemologia das virtudes que Pritchard está assumindo para explicar a condição da habilidade é a epistemologia das virtudes de inspiração confiabilista. Ela também é paradigmaticamente externalista, pois qualquer propriedade análoga à justificação epistêmica será determinada puramente por fatores externos (e inacessíveis, no sentido relevante) à vida mental do sujeito. De acordo com a epistemologia das virtudes, $S$ só sabe que $P$ quando exerce as suas habilidades cognitivas ao crer que $P$. Quando tratávamos do caso Fake Barns, vimos que habilidades cognitivas devem ser relativizadas ao ambiente em que são exercidas e propriamente instanciadas somente se exibem confiabilidade. Não é possível para internalistas que o análogo mais próximo à justificação epistêmica seja determinado por fatores externos à vida mental do sujeito.

\section{Observações conclusivas}

Embora a epistemologia das virtudes antissorte de Pritchard aparentemente explique o fenômeno da gettierização e acomode os casos problemáticos que examinamos, ela o faz a um custo alto. Pritchard precisa invocar uma explicação sobre a relação de atribuição de crédito à agencia cognitiva do sujeito cognoscente, o que se mostra um problema, visto que todas as explicações sobre tal relação sofrem objeções, como apontamos anteriormente. Pritchard precisa também invocar as noções não epistêmicas de virtude, habilidade e sucesso, noções estas cuja interpretação e o emprego em uma análise do conhecimento são questionáveis, como também apontamos. Além disso, Pritchard precisa comprometer-se com um princípio de segurança e com uma explicação modal para tal princípio; lembremo-nos que tentativas neste sentido são pressionadas por objeções fortes na literatura. Nós apresentamos uma alternativa que não é pressionada pelas dificuldades que se colocam à proposta de Pritchard: a teoria da anulabilidade. Nós apresentamos razões para crer que a teoria da anulabilidade 
(i) preserva uma economia conceitual que conta a seu favor, pois dispensa noções não epistêmicas e assim não importa os seus problemas, e (ii) é neutra quanto ao debate internalismo vs. externalismo, pois é compatível com qualquer noção de justificação epistêmica para explicar a posse de conhecimento.

\section{Referências}

Comesaña, J. 2005. Unsafe knowledge. Synthese 146(3): 395-404.

Conee, E.; Feldman, R. 2004. Evidentialism. New York: Oxford University Press.

de Almeida, C. (a ser publicado). Knowledge, Benign Falsehoods, and the Gettier Problem. In: Borges, R.; de Almeida, C.; Klein, P. (eds.) Explaining Knowledge: New Essays on the Gettier Problem. Oxford: Oxford University Press.

de Almeida, C.; Fett, J. R. 2016. Defeasibility and gettierization: a reminder. Australasian Journal of Philosophy 94(1): 152-169.

Engel, M. 1992. Is epistemic luck compatible with knowledge? Southern Journal of Philosophy 30(2): 59-75.

Foley, R. 2012. When is True Belief Knowledge? Princeton, NJ: Princeton University Press.

Goldman, A. 1976. Discrimination and perceptual knowledge. Journal of Philosophy 73: 771791.

Greco, J. 2010. Achieving Knowledge: A Virtue-Theoretic Account of Epistemic Normativity. Cambridge: Cambridge University Press.

- 2012a. A (Different) Virtue Epistemology. Philosophy and Phenomenological Research 85(1): 1-26.

- 2012b. Better safe than sensitive. In: Becker, K.; Black, T. (eds.) The Sensitivity Principle in Epistemology, pp.193-206. Cambridge: Cambridge University Press.

Harman, G. 1968. Knowledge, Inference, and Explanation. American Philosophical Quarterly 5(3): 164-173.

Hiller, A.; Neta, R. 2007. Safety and epistemic luck. Synthese 158(3): 303-313.

Klein, P. 1981. Certainty, a Refutation of Scepticism. Minneapolis: University of Minnesota Press.

- 2008. Useful False Beliefs. In: Smith, Q. (ed) Epistemology: New Essays, pp.25-61. Oxford: Oxford University Press.

- 2012. What Makes Knowledge the Most Highly Prized Form of True Belief. In: Becker, K.; Black, T. (eds.) The Sensitivity Principle in Epistemology, pp.152-169. Cambridge: Cambridge University Press.

—. (a ser publicado). The Nature of Knowledge. In: Borges, R.; de Almeida, C.; Klein, P. (eds.) Explaining Knowledge: New Essays on the Gettier Problem. Oxford: Oxford University Press.

Lackey, J. 2007. Why we don't deserve credit for everything we know. Synthese 158(3): 345361.

- 2009. Knowledge and credit. Philosophical Studies 142(1): 27-42.

Lehrer, K. 1965. Knowledge, Truth and Evidence. Analysis 25(5): 168-175.

Lehrer, K.; Paxson, T. 1969. Knowledge: Undefeated justified true belief. Journal of Philosophy 66(8): 225-237.

Principia 20(2): 179-200 (2016). 
Pritchard, D. 2007. Anti-luck epistemology. Synthese 158(3): 277-297.

. 2012. Anti-Luck Virtue Epistemology. Journal of Philosophy 109(3): 247-279.

. 2014. Knowledge Cannot Be Lucky. In: Steup, M.; Turri, J.; Sosa, E. (eds.). Contemporary Debates in Epistemology $2^{\text {nd }}$ ed. Blackwell.

Russell, B. 1948. Human Knowledge: Its Scope and Limits. New York: Allen and Unwin.

Sosa, E. 1999. How to defeat opposition to Moore. Philosophical Perspectives 13(13): 137149.

- 2007. A Virtue Epistemology: Volume I: Apt Belief and Reflective Knowledge. Oxford: Oxford University Press.

- 2010. How competence matters in epistemology. Philosophical Perspectives 24(1): $465-475$.

Turri, J. 2011. Manifest Failure: The Gettier Problem Solved. Philosophers' Imprint 11(8).

2012. In Gettier's wake. In: Hetherington, S. (ed.) Epistemology: The Key Thinkers, pp.214-229. New York, NY: Continuum.

Unger, P. 1968. An analysis of factual knowledge. Journal of Philosophy 65(6): 157-170.

Williamson, T. 2000. Knowledge and its limits. New York, NY: Oxford University Press.

Zagzebski, L. 2009. On Epistemology. Belmont, CA: Wadsworth.

JoÃo RizZio VicEnTE FETT

Departamento de Filosofia

Pontifícia Universidade Católica do Rio Grande do Sul (PUCRS)

jrfett01@gmail.com

\section{Notas}

${ }^{1} \mathrm{O}$ rótulo 'sorte epistêmica verítica' é a tradução para 'veritic epistemic luck', o qual Duncan Pritchard usa para se referir ao tipo de sorte específico que é incompatível com a posse de conhecimento, a saber, a sorte que tem a ver com a verdade da crença. Pritchard toma esse rótulo de Mylan Engel (1992). O neologismo 'verítica' nos pareceu o mais adequado para transmitir tal ideia - de alcance fortuito da verdade - pretendida por Pritchard, uma vez que os correlatos em português para 'veritic' (verídica, veraz, verdadeira) não expressam adequadamente a ideia original do termo. Tais adjetivos - como 'verídica', 'veraz', e 'verdadeira' — qualificariam o tipo de sorte em questão como tendo a propriedade de ser verdadeira, e não é isto que se pretende. Por essa razão, optamos pela tradução mecânica/técnica, que se assemelha ao termo na língua original e captura uma ideia que não seria capturada por outro termo em português.

${ }^{2}$ Mundos possíveis são, grosseiramente, os modos como o mundo poderia ter sido; são os diferentes cenários que poderiam se dar. Um desses modos é, de fato, o modo como o mundo é: este é o mundo atual. Os mundos possíveis, exceto o atual, podem ser compreendidos por meio da descrição de situações contrafactuais (Cf. Greco 2012b). Por exemplo, no mundo atual, eu estou usando uma camisa amarela e sou brasileiro, mas eu poderia ter vestido uma camisa azul e ser argentino; a situação contrafactual em que eu estou usando uma camisa azul e sou argentino é um mundo possível. Os mundos possíveis são ordenados por uma relação de proximidade com o mundo atual. À medida que há mais mudanças nas características e

Principia 20(2): 179-200 (2016). 
descrições de um mundo possível, mais distante este mundo está do mundo atual. A condição de segurança sugere que você sabe que $P$ só se nas situações contrafactuais próximas, onde há poucas variações em relação ao mundo atual, se você crê por meio da mesma base como no mundo atual, então você crê verazmente.

${ }^{3}$ Formulamos o teste do princípio de segurança nesse grau de generalidade - falando da crença que o sujeito formaria nos mundos possíveis próximos, e não da crença em $P$ nesses mundos - devido aos problemas que podem surgir com respeito às crenças em verdades necessárias. Nestes casos, é impossível que o sujeito creia falsamente na proposição-alvo e, portanto, o teste de segurança fica comprometido. Veja esta objeção ao princípio de segurança e a solução adotada por Pritchard (2014, pp.157-158).

${ }^{4}$ Aqui, uma suposição arriscada (do nosso ponto de vista) precisa ser assumida, a saber, que a descrição do método de formação de crenças empregado por Temp no mundo atual deve ser mais ou menos como a seguinte: "Consultar um termômetro quebrado num ambiente em que há um agente ajustando o que este termômetro mostra à temperatura real da sala". Por essa razão, o caso Temp parece nos comprometer com a suposição de que a descrição dos mundos próximos ao mundo atual nos quais Temp forma crenças sobre a temperatura da sala deve incluir a presença do agente escondido, não apenas a percepção do termômetro quebrado. Porém, esta suposição é, no mínimo, controversa.

${ }^{5}$ A ideia é que Alvin acaba com crença verdadeira justificada pelo menos por padrões externalistas de justificação. Afinal, Alvin não tem qualquer evidência para a sua crença-alvo.

${ }^{6}$ Neste caso, não parece haver qualquer suposição arriscada sobre o método de formação de crença empregado por Alvin, ao contrário do caso Temp. Veja a nota 4.

${ }^{7}$ Obviamente, os juízos sobre o status justificacional variam à medida que variam as intuições sobre as condições para a posse de justificação e conhecimento.

${ }^{8}$ As dificuldades enfrentadas pela epistemologia das virtudes forte ao assumir que habilidades devem ser relativizadas aos ambientes são expostas em Pritchard (2012, pp.267-269).

${ }^{9}$ Como já foi dito, as epistemologias da virtude encontram dificuldade em explicar a relação de atribuição sem ser pressionadas por objeções. Este é o principal entrave para o funcionamento das suas respostas ao problema de Gettier. Há diversos modos de se entender a relação de atribuição, não obstante objeções. Veja Greco (2012a, pp.5-17). Vamos voltar a essa questão mais adiante.

${ }^{10}$ Richard Foley propõe uma teoria do conhecimento cujo núcleo é exatamente a ideia de que um sujeito, $S$, sabe que $P$ somente se não há verdades importantes sobre $P$ ignoradas por ele. Veja Foley (2012).

${ }^{11}$ Este ponto é feito originalmente em De Almeida e Fett (2016, pp.164-167).

12 Aqui, nós apenas apontamos haver tais problemas. Infelizmente, articular essas objeções adequadamente não cabe no escopo deste ensaio. Para um tratamento destas e de outras objeções às epistemologias modais/contrafactuais, veja Comesaña (2005), e Hiller e Neta (2007).

${ }^{13}$ Uma proposta mais recente, porém menos popular, encontra-se em Greco (2012a), cuja teoria é que a relação de atribuição é pragmática. Examinar a proposta de Greco é uma tarefa que não cabe no escopo deste ensaio.

Principia 20(2): 179-200 (2016). 